\title{
Immunogold Labeling of Hrp Pili of Pseudomonas syringae pv. tomato Assembled in Minimal Medium and In Planta
}

\author{
Wenqi Hu, ${ }^{1,2}$ Jing Yuan, ${ }^{1}$ Qiao-Ling Jin, ${ }^{1,2}$ Patrick Hart, ${ }^{2}$ and Sheng Yang He ${ }^{1,2}$ \\ ${ }^{1}$ Department of Energy Plant Research Laboratory, Michigan State University, East Lansing 48824, U.S.A.; \\ ${ }^{2}$ Department of Botany and Plant Pathology, Michigan State University, East Lansing 48824, U.S.A. \\ Accepted 1 November 2000.
}

\begin{abstract}
Hypersensitive reaction and pathogenicity (hrp) genes are required for Pseudomonas syringae pv. tomato (Pst) DC3000 to cause disease in susceptible tomato and Arabidopsis thaliana plants and to elicit the hypersensitive response in resistant plants. The hrp genes encode a type III protein secretion system known as the Hrp system, which in Pst DC3000 secretes HrpA, HrpZ, HrpW, and AvrPto and assembles a surface appendage, named the Hrp pilus, in hrp-gene-inducing minimal medium. HrpA has been suggested to be the Hrp pilus structural protein on the basis of copurification and mutational analyses. In this study, we show that an antibody against HrpA efficiently labeled Hrp pili, whereas antibodies against HrpW and HrpZ did not. Immunogold labeling of bacteria-infected Arabidopsis thaliana leaf tissue with an Hrp pilus antibody revealed a characteristic lineup of gold particles around bacteria and/or at the bacterium-plant contact site. These results confirm that HrpA is the major structural protein of the Hrp pilus and provide evidence that Hrp pili are assembled in vitro and in planta.
\end{abstract}

Additional keywords: avirulence gene, disease resistance, EPEC, Salmonella spp., Shigella spp., Yersinia spp.

Hypersensitive reaction and pathogenicity $(h r p)$ genes are required for several gram-negative bacterial pathogens, including Pseudomonas syringae, to cause disease in susceptible plants and to elicit hypersensitive response (HR) in resistant plants (Lindgren 1997). Many hrp genes are involved in the regulation and assembly of a type III protein secretion system, also known as the Hrp system, that transfers bacterial proteins to the extracellular space or directly into plant cells (Alfano and Collmer 1997; Bonas 1994; Galan and Collmer 1999; He 1998; Hutcheson 1999; Lindgren 1997; Mudgett and

Corresponding author: S. Y. He; Telephone: +1-517-353-9181; Fax: +1-517-353-9168; E-mail: hes@msu.edu

Present address of W. Hu: Department of Microbiology and Immunology, School of Medicine and Dentistry, University of Western Ontario, N6A 5C1 Canada.

Present address of J. Yuan: Departments of Medicine and Microbiology and Molecular Genetics, Channing Laboratory, Harvard University, 181 Longwood Avenue, Boston, MA 02115, U.S.A.
Staskawicz 1998; Van Gijsegem et al. 1993). In P. syringae, there are at least 27 genes in the core $h r p$ gene cluster, nine of which have counterparts in several plant and mammalian pathogenic bacteria such as Erwinia amylovora, Xanthomonas campestris, Ralstonia solanacearum, Yersinia spp., Salmonella spp., and Shigella spp. (Alfano and Collmer 1997; He 1998; Huang et al. 1995; Hutcheson 1999). Eight of these nine genes show significant sequence similarities with genes involved in the assembly of the flagellar basal body structure, suggesting possible structural and functional similarities between flagellar assembly and type III protein secretion. These nine $h r p$ genes have been renamed $h r c$ (for $h r p$ gene conserved) (Bogdanove et al. 1996). Indeed, the Salmonella typhimurium type III secretion structure was found to resemble the flagellar basal body (Kubori et al. 1998). Specifically, it is composed of outer and inner rings that are located in the outer and inner membranes, respectively, and a short, needlelike extracellular extension (Kubori et al. 1998). The type III secretion structure also has been visualized in Shigella flexneri (Blocker et al. 1999).

In $P$. syringae pv. tomato (Pst) strain DC3000, the Hrp system secretes the following endogenous or heterologous virulence and avirulence proteins in hrp-gene-inducing minimal broth: HrpA, HrpZ, HrpW, AvrPto, and AvrRpt2 (Charkowski et al. 1998; Mudgett and Staskawicz 1999; Roine et al. 1997; Van Dijk et al. 1999; Wei et al. 2000; Yuan and He 1996). In solid hrp-inducing minimal medium, Pst DC3000 assembles a pilus named the Hrp pilus (Roine et al. 1997). Assembly of the Hrp pilus is dependent on hrp genes. The extracellular HrpA protein is copurified with Hrp pili and mutation in the hrpA gene blocks the assembly of Hrp pili. On the basis of these results, it was suggested that HrpA is a structural protein of the Hrp pilus (Roine et al. 1997). The hrpA mutant was unable to cause disease in the host plant Arabidopsis thaliana, to elicit the HR in the nonhost tobacco, or presumably to deliver the AvrB or AvrPto protein into the plant cell (Roine et al. 1997). Thus, the $h r p A$ gene plays a critical role in plantPst DC3000 interactions. The absolute requirement of the hrpA gene for plant-Pst DC3000 interactions is because this pilus gene is necessary for secretion of Hrp and Avr proteins and for maximal expression of $h r p$ and $a v r$ genes in Pst DC3000 (Wei et al. 2000). Recently, Van Gijsegem et al. (2000) reported an hrp-dependent pilus in Ralstonia solanacearum. They made the important observation that the Hrp 
pilus in $R$. solanacearum was required for type III protein secretion but not for bacterial attachment to host cells.

In this study, we further examined the association of the secreted HrpA, HrpW, and HrpZ proteins with the Hrp pilus by immunogold labeling. We then addressed the question of whether Hrp pili are assembled in bacteria-infected plant tissue.

\section{RESULTS}

\section{Construction of a flagellum-minus mutant of Pst DC3000.}

Pst DC3000 produces two surface appendages under hrp gene-inducing conditions: Hrp pili and flagella (Roine et al. 1997). Hrp pili with a diameter of 8 to $10 \mathrm{~nm}$ are produced at random locations on the surface of Pst DC3000 bacteria in vitro, whereas one to two flagella with a diameter of 15 to 18 $\mathrm{nm}$ are produced at one end (Fig. 1A). Although the two appendages differ in diameter, they were difficult to distinguish when detached from bacteria, which often occurs during sample preparation for immunogold labeling experiments. To facilitate immunogold labeling analysis of the Hrp pilus, we created a flaA mutant of Pst DC3000, which does not produce flagellin or flagellar filament (Fig. 1C; see below for cloning and mutagenesis procedures). The flaA mutant still elicited HR in tobacco, caused disease in A. thaliana and produced the wild-type amounts of Hrp pili in $h r p$-inducing agar plates. A flaAhrpA double mutant also was created for use as a control in the immunogold labeling experiments. The flaAhrpA mutant produced neither flagellar filaments nor Hrp pili (Fig. 1D)
A

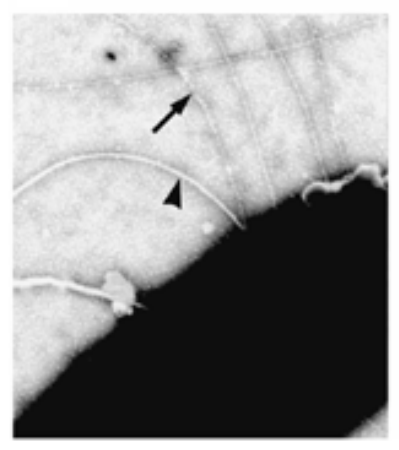

B

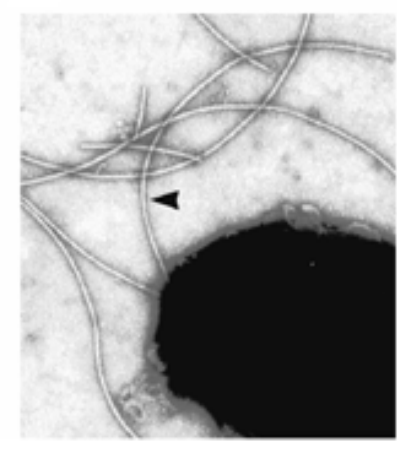

C

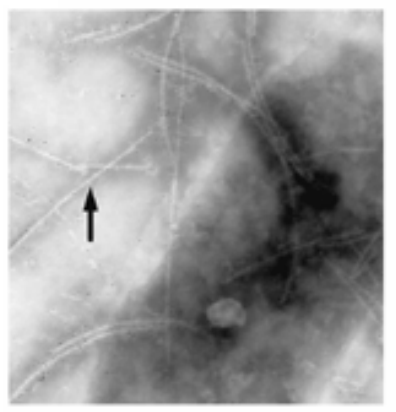

D

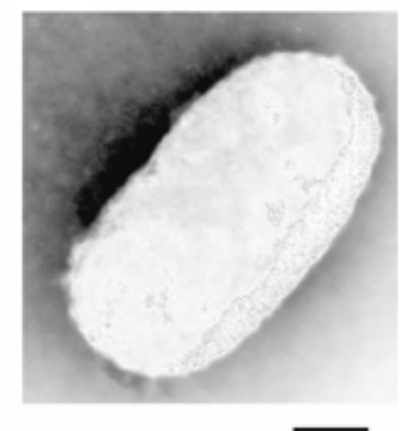

Fig. 1. Transmission electron microscopy examination of DC3000 and its mutants. A, DC3000; B, hrpA; C, flaA; and D, flaAhrpA grown on $h r p$-inducing medium were examined after staining with $1 \%$ potassium phosphotungstic acid $(\mathrm{pH} 6.5)$. Arrowheads = flagella $(15$ to $18 \mathrm{~nm}$ in diameter $)$. Arrows $=$ Hrp pili $(8$ to $10 \mathrm{~nm}$ in diameter $)$. Bar $=100 \mathrm{~nm}$. and could no longer cause disease in A. thaliana or elicit HR in tobacco.

\section{Immunogold labeling of Hrp pili assembled in $\boldsymbol{h r p}$-inducing minimal agar medium.}

Polyclonal rabbit antibodies against partially purified Hrp pili and gel-purified HrpA were produced. One batch of Hrp pilus antibody that was used in this study reacted with HrpA and a $19-\mathrm{kDa}$ protein in the Hrp pilus preparation from the flaA mutant (Fig. 2A). Neither protein was detected in a similar preparation from the flaAhrpA mutant that does not produce the flagellar filament or the Hrp pilus (Fig. 2A). The identity of the 19-kDa protein is unknown. Its apparent molecular mass and association with the Hrp pilus suggests that it may be a dimer of the HrpA protein, which tends to aggregate in vitro (Roine et al. 1998), or another protein associated with the Hrp pilus. The HrpA antibody, however, detected the HrpA protein only in the Hrp pilus preparation from the flaA mutant, which argues against the possibility that the $19-\mathrm{kDa}$ protein was a dimer of the HrpA protein. No proteins were detected by the HrpA antibody in the Hrp pilus preparation from the flaAhrpA mutant (Fig. 2B). Both antibodies efficiently decorated Hrp pili isolated from $h r p$-induced cultures of the flaA mutant. Gold particles densely attached to Hrp pili (Fig. 3A and B).

In addition to HrpA, two other proteins, HrpW and HrpZ, are abundantly secreted by Pst DC3000 in hrp-inducing minimal broth and agar plates (Brown et al. in press; Charkowski et al. 1998; Wei et al. 2000; Yuan and He 1996). To

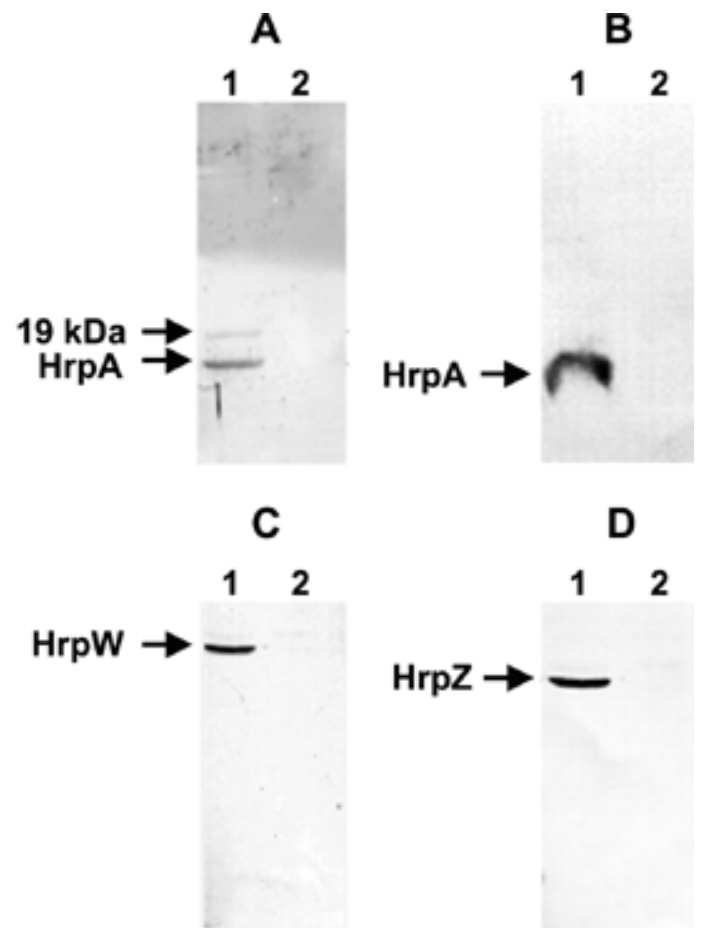

Fig. 2. Immunoblot analysis of antibodies used in this study. A, Immunoblotting of cell surface proteins of flaA (lane 1) and flaAhrpA (lane 2) mutants with antibodies against $\operatorname{Hrp}$ pili (A) and $\operatorname{HrpA}(\mathbf{B})$. Immunoblotting of proteins secreted in hrp-inducing broth cultures of Pseudomonas syringae pv. tomato strain DC3000 (lane 1) and the hrpS mutant (lane 2) by HrpW (C) and HrpZ (D) antibodies. 
determine whether the secreted HrpW and HrpZ proteins are associated with Hrp pili, we performed immunogold labeling of Hrp pili with HrpW and HrpZ antibodies. The HrpW and HrpZ antibodies were prepared against purified HrpW and HrpZ proteins, respectively, of $P$. syringae pv. syringae 61 . These antibodies, however, reacted with the HrpW or HrpZ protein of Pst DC3000 (Fig. 2C and D), and neither the HrpW nor HrpZ antibody bound tightly or in large numbers to Hrp pili recovered from hrp-inducing agar medium (Fig. 3C and D), although occasionally a few gold particles were found attached to Hrp pili without any particular patterns.

\section{Ultrastructural examination}

\section{of $A$. thaliana leaf tissue infected with bacteria.}

To examine possible host cell wall degradation in Pst DC3000-infected plant tissues, we made ultrathin sections (70 to $90 \mathrm{~nm}$ thick) of $A$. thaliana leaves collected at various times after infiltration with the Pst DC3000 flaA or flaAhrpA mutant. We found that $A$. thaliana cell walls were not degraded during the entire 8-h sampling period before tissue necrosis (Fig. 4A to F). Thus, the Hrp system of Pst DC3000 apparently must deliver proteins into the host cell through an apparently intact cell wall, although subtle changes in the host cell wall would have escaped our detection. Bacteria were found in abundant numbers in the plant intercellular space at all time points. Granular deposits of an unknown origin frequently were found at contact sites between bacteria (fla $A$ and flaAhrpA mutants) and plant cells. The curvature of these deposits indicated close contact of some bacteria with plant cells

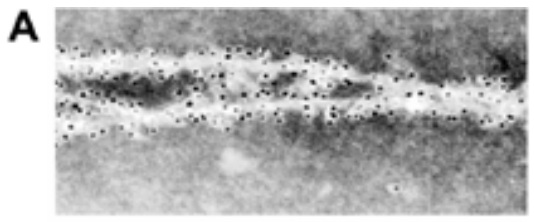

B
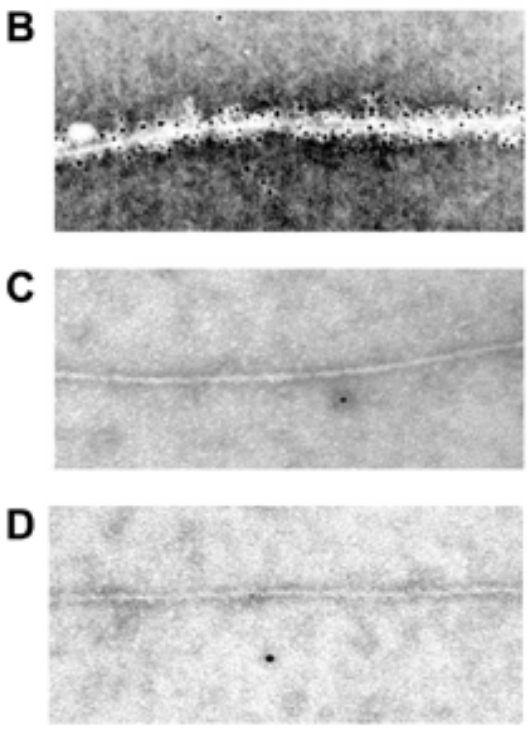

Fig. 3. Immunogold labeling of Hrp pili produced by the flaA mutant in $h r p$-inducing medium. A, Hrp pili decorated with the Hrp pilus antibody. B, Hrp pili decorated with the HrpA antibody. C, Hrp pili after labeling with the HrpW antibody. D, Hrp pili after labeling with the HrpZ antibody. Two-day-old agar cultures of the flaA mutant were used for these labeling experiments. before tissue fixation. Application of vacuum and uneven shrinkage of bacteria, the deposits, and plant cell walls during tissue fixation, however, often caused bacteria and the deposits to appear slightly separated (Fig. 4A to F).

\section{Immunogold labeling of Hrp pili assembled in planta with the HrpA antibody.}

The Hrp pilus antibody was used to examine the formation of Hrp pili in planta. We examined over 500 ultrathin sections of $A$. thaliana leaves infected with either the Pst DC3000 flaA or the flaAhrpA mutant. In general, the number of gold particles in ultrathin sections of bacteria-infected $A$. thaliana leaves was very low. Gold particles were present in significant numbers only in the flaA mutant-inoculated leaf tissue at $2 \mathrm{~h}$ postinoculation and later. The significant increase in gold particles at $2 \mathrm{~h}$ postinoculation and later in the plant tissue infected with the flaA mutant is consistent with the induction kinetics of hrp gene expression observed previously (Rahme et al. 1992; Xiao et al. 1992). The gold particles were found mainly near the bacteria-plant contact sites, around bacteria, or in the host cell wall, but were not distributed randomly in the apoplast (Fig. 4B to F). Not every bacterium was labeled. There was a tendency that bacteria near host cells were labeled more frequently than those away from host cells. The distribution of gold particles in 12 randomly chosen images that contained bacteria closely associated with the host cell wall was $57.8 \%$ on the bacterial surface or immediately around bacteria, $23.1 \%$ inside bacteria, $18.1 \%$ in the host cell wall (almost exclusively near bacteria), and $0.01 \%$ randomly distributed in the intercellular space away from bacteria.

Localization of the great majority of gold particles around the bacteria but not randomly in the intercellular space suggests localization of HrpA mainly on the bacterial surface. Furthermore, the gold particles near the bacteria-plant contact sites or around bacteria were often arranged in short (Fig. 4B and D) or long strings (Fig. 4C, E, and F), providing evidence for assembly of Hrp pili in planta. In one ultrathin section, we observed gold particles localized to a pilus-like structure (Fig. $4 \mathrm{E}$ and $\mathrm{F}$ ). The diameter of the pilus-like structure detected in Fig. 4F was about $12 \mathrm{~nm}$, which is larger than that of the Hrp pilus formed in vitro. It is not known whether this difference reflects different structural compositions of the filaments formed in vitro versus in vivo or results from different treatments during sample preparation for negative staining (for visualizing Hrp pili in vitro) versus immunogold labeling (for visualizing Hrp pili in vivo). Some gold particles were localized in the host cell wall (Fig. 4C and D), although no discernible pilus structures were associated with these gold particles. In Figure 4F, the pilus-like structure appears to extend into the host cell wall, whereas the gold particles were observed only along the pilus-like structure between the bacterium and the host cell wall but not within the host cell wall. No pilus-like filaments or characteristic lineup of gold particles were observed in the negative control sections containing the flaAhrpA mutant bacteria.

\section{DISCUSSION}

Previously, the extracellular HrpA protein was suggested to be a structural protein of the Hrp pilus on the basis of copurification, genetic, and self-assembly experiments (Roine et al. 
1997; Roine et al. 1998). In this study, we showed that an HrpA antibody densely labeled the Hrp pilus, providing direct evidence that HrpA is the major structural protein of the Hrp pilus. We do not know, however, whether HrpA is the only structural protein of the Hrp pilus or whether there are other minor subunits. The F pilus, which is required for the conjugative transfer of DNA between bacteria, apparently consists of only one pilin protein (Willetts and Skurray 1980), whereas the adhesive P pilus of Escherichia coli has one major subunit that makes up the main filament and several minor subunits on the pilus tip (Soto and Hultgren 1999). An antibody developed against partially purified Hrp pili detects the HrpA protein as well as a $19-\mathrm{kDa}$ protein (Fig. 2), which is correlated with the appearance of Hrp pili. Whether or not this protein is another subunit of the Hrp pilus or the HrpA dimer remains to be determined. The fact that the HrpA antibody does not label this protein (Fig. 2B), however, argues against the latter possibility. We also have other batches of Hrp pilus antibodies that reacted with additional proteins that are $h r p$-dependent (data not shown), although the association of these additional proteins was quite sensitive to conditions used to purify Hrp pili.

Antibodies raised against HrpW and HrpZ did not label Hrp pili formed in $h r p$-inducing minimal agar medium (Fig. 3C and D). Therefore, these two extracellular Hrp proteins are not likely subunits of the Hrp pilus, although their association with the Hrp pilus assembled in planta cannot be excluded. Attempts to localize the HrpW and HrpZ proteins in planta were unsuccessful. There were high levels of random background labeling of HrpW and HrpZ in A. thaliana leaf tissue infected with the Pst DC3000 flaA or flaAhrpA mutant (W.
$\mathrm{Hu}, \mathrm{P}$. Hart, and S. Y. He, unpublished results). Furthermore, the HrpW antibody bound to the A. thaliana cell wall, with or without bacterial inoculation (W. Hu, P. Hart, and S. Y. He, unpublished results). Previous studies indicated that purified HrpZ and HrpW interact with plant cell walls on the basis of confocal microscopic examination (Hoyos et al. 1996) and in vitro cell wall binding assays (Charkowski et al. 1998). Further investigation is needed to confirm whether this type of interaction also occurs in bacteria-infected plant tissues. This may be achieved by immunogold localization of HrpW and HrpZ in bacteria-infected plant tissues with alternative antibodies (e.g., epitope antibodies). It is interesting to note that the E. amylovora $\mathrm{HrpN}$ protein is secreted in apple seedling tissue (Perino et al. 1999).

Prior to this study, assembly of Hrp pili was observed only in artificial $h r p$-inducing medium. Here we provide evidence that Pst DC3000 also assembles the Hrp pilus in vivo around bacteria and/or at the bacterium-host contact site (Fig. 4B to F). Whether the Hrp pilus actually penetrates the host cell wall is less clear. We did observe gold particles (Fig. 4C and D) and a pilus-like filament in the host cell wall (Fig. 4F). In contrast to the ease of labeling of the intact Hrp pili without ultrathin sectioning, immunogold labeling of Hrp pili after ultrathin sectioning proved to be very difficult. We had foreseen three technical problems with immunogold labeling of the pilus structure formed in planta. First, for a relatively long Hrp pilus to be visible, the orientation of the pilus and the section plane have to be the same (Fig. 5). The ultrathin nature of the Hrp pilus drastically decreases the chance of obtaining the longitudinal section images of a relatively intact filament.
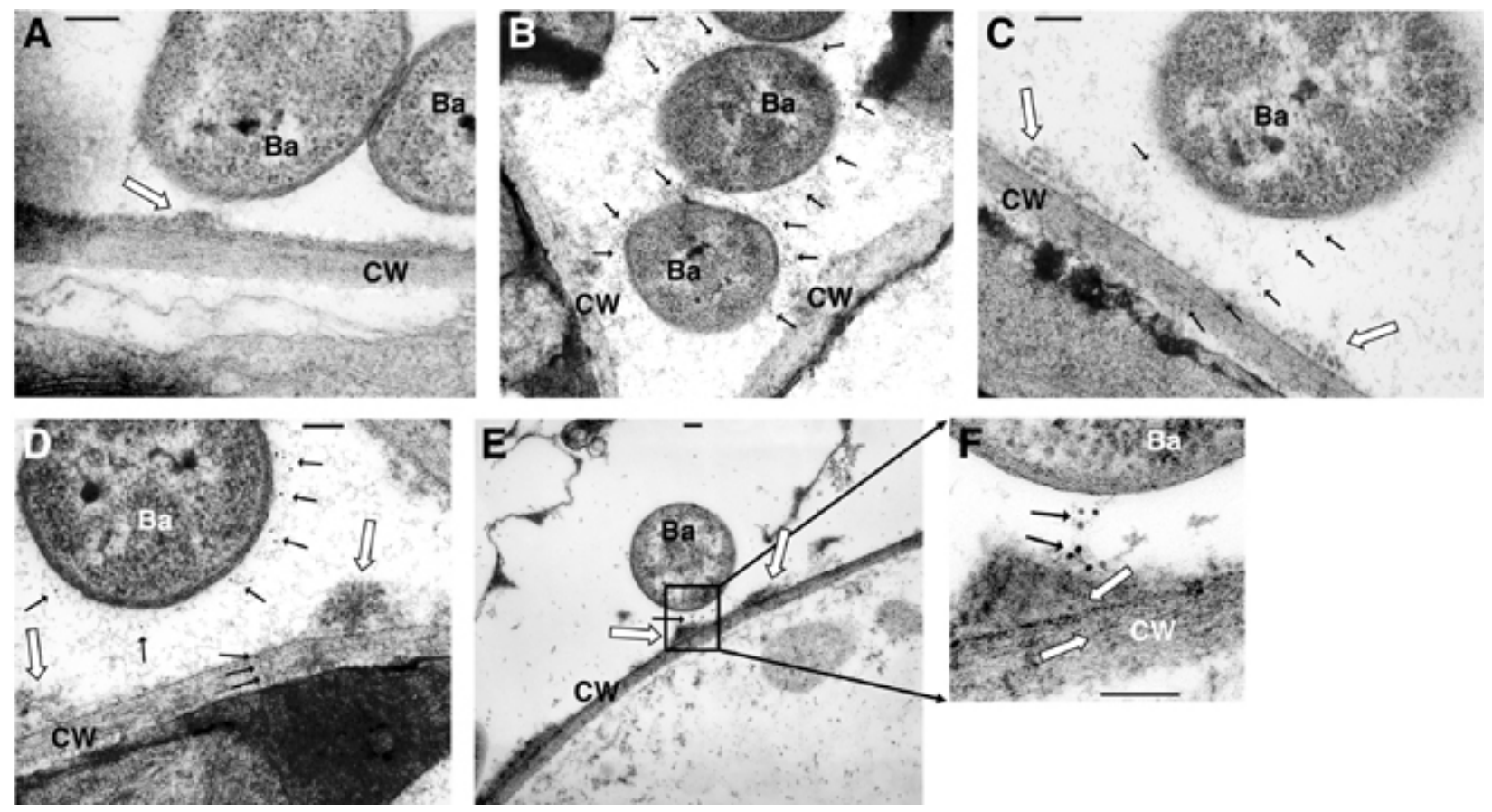

Fig. 4. Immunogold labeling of Hrp pili assembled in planta. A, Image of Arabidopsis thaliana leaf tissue infected with the flaAhrpA mutant (negative control). Ba: bacterium; CW: host cell wall; Open arrows in $\mathbf{A}$ to $\mathbf{E}$ indicate deposits of unknown origin at the presumed host-bacteria contact sites. Bar $=100 \mathrm{~nm}$. B to F, Selected images of A. thaliana leaf tissue infected by the Hrp pilus-producing flaA mutant. Arrows indicate 10 -nm gold particles, which in $\mathbf{B}$ and $\mathbf{D}$, were mainly around the bacteria and in $\mathbf{C}, \mathbf{E}$, and $\mathbf{F}$, arranged in a somewhat linear fashion. E, Image showing a generally low level of nonspecific labeling away from the host-bacteria contact sites, which is enlarged to show a characteristic lineup of gold particles between the bacterium and host cell wall and an apparent filament (indicated by open arrows in F) penetrating the host cell wall. Images are from leaf tissues collected $4 \mathrm{~h}$ postinoculation. The $A$. thaliana cell wall remains intact at $8 \mathrm{~h}$ postinoculation when inoculated leaves were about to undergo tissue collapse. 
Second, the thinnest section we could make with the available diamond knife was 70- to 90-nm thick. Even if the electron density of the pilus was very different from the background plant cell wall materials, the electron density difference would be greatly reduced by the bulk plant cell wall materials (at least $60-\mathrm{nm}$ thick) above and/or below the pilus (8- to $10-\mathrm{nm}$ thick) in the section. Third, only those pilus parts that were exposed on the section surface would be available for antibody labeling. Therefore, a pilus would be labeled along its entire length only if it were horizontally positioned in an ultrathin section and perfectly sectioned throughout its entirety. We believe that these are the reasons for the detection of mainly short strings of gold particle lineup rather than long Hrp pili in bacteria-infected tissue.

No drastic changes to the $A$. thaliana leaf cell wall were observed during the 8-h experimental period before the onset of tissue necrosis (Fig. 4). Our observation was consistent with previous ultrastructural studies that showed intact plant cell walls in several other plant-bacteria interactions (Goodman 1982). An apparently intact host cell wall implies that the type III protein secretion system of Pst DC3000 somehow must deliver proteins into the host cell through an intact, but likely modified, plant cell wall. The mechanism by which Pst DC3000 and other plant pathogenic bacteria overcome the host cell wall barrier remains a mystery. Similar problems exist for two other macromolecular trafficking systems: bacterial conjugation, in which the recipient cell is a wall-bound bacterium (Willetts and Skurray 1980), and Agrobacterium tumefaciens (Fullner et al. 1996), which transports proteins and T-DNA into wall-bound plant cells. Interestingly, in bacterial conjugation and T-DNA transport by A. tumefaciens, a pilus is required. Pili may be indirectly involved in macromolecular trafficking by mediating contact between donor and recipient cells or they are directly involved in the secretion of proteins and DNA by providing a conduit or guiding filament (He 1997). Recently, we have shown that the Hrp pilus structural gene $(h r p A)$ is required for Pst DC3000 to secrete Hrp and Avr proteins in culture in the absence of recipient host cells (Wei et al. 2000). Similarly, Van Gijsegem et al. (2000) have shown that the Hrp pilus in $R$. solanacearum is required for secretion of PopA but not for bacterial attachment to host cells. These data provide strong support for a direct involvement of Hrp pili in protein transfer.

It is important to note that long, filamentous pili are not required for type III protein secretion in human and animal pathogenic bacteria, which target recipient cells lacking a cell wall, although a short, needlelike filament is found to be part of the type III secretion structure in S. typhimurium and $S$. flexneri (Blocker et al. 1999; Kubori et al. 1998). It is possible that these short needle filaments are functionally equivalent to Hrp pili on the basis of their similar diameters. S. typhimurium and enteropathogenic $E$. coli also transiently produce thick filamentous appendages (50 to $60 \mathrm{~nm}$ in diameter) upon contact with host cells in a type III secretion-dependent manner (Ginocchio et al. 1994; Knutton et al. 1998). These thick filaments have been suggested to be involved in the delivery of effector proteins into the host cell. The EspA filament appears to be composed of pili (Ebel et al. 1998; Knutton et al. 1998; S. Knutton, personal communication), raising the intriguing possibility that pili or pilus-based filaments are the basic extracellular structure for type III protein delivery in plant and animal pathogenic bacteria.

\section{MATERIALS AND METHODS}

\section{Bacterial strains and growth conditions.}

The bacterial strains used in this study are listed in Table 1 . Bacteria were grown in Luria-Bertani (LB) or hrp-inducing
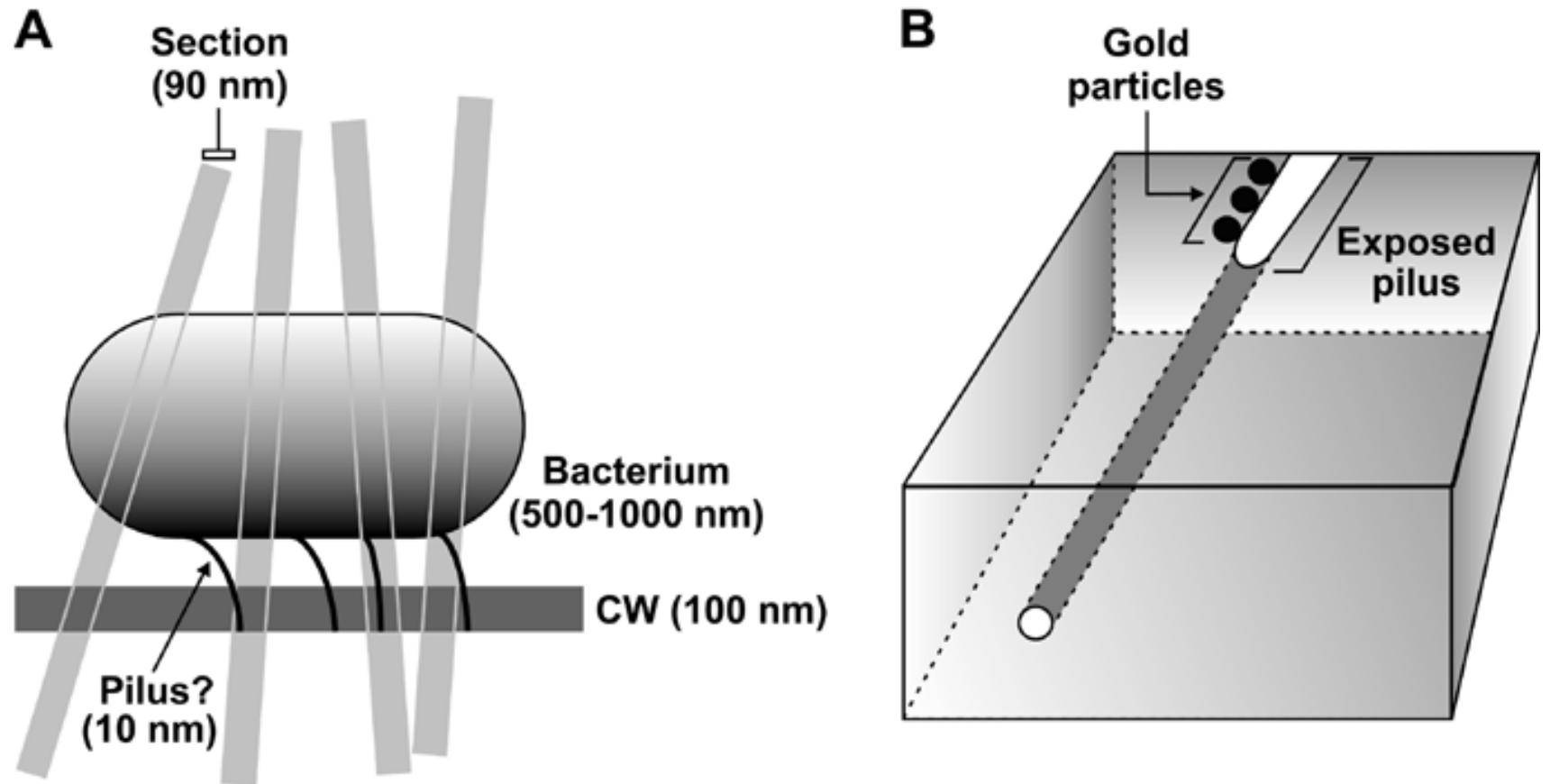

Fig. 5. Schematic representation of ultrathin sectioning and immunogold-labeling of Hrp pili in bacteria-infected plant tissue. A, Hypothetical sectioning of a Hrp-pilus-producing bacterium near the plant cell wall $(\mathrm{CW})$. B, Hypothetical labeling of an ultrathin section that contains a piece of pilus. 
minimal agar plates, as described previously (Roine et al. 1997). Also used were $100 \mathrm{mg}$ of rifampicin and $50 \mathrm{mg}$ of kanamycin per liter.

\section{Preparation of antibodies against Hrp pili and HrpA.}

Hrp pili were purified from a Pst DC3000 cell surface through sucrose gradient, as described previously (Roine et al. 1997). For preparation of an antibody against Hrp pili, $1 \mathrm{mg}$ of partially purified Hrp pili was suspended in $2 \mathrm{ml}$ of a 1:1 mix of phosphate-saline buffer and Freund's complete adjuvant (Sigma, St. Louis, MO, U.S.A.). The Hrp pilus suspension was injected intradermally into female white rabbits. Three boosts were administered intramuscularly at 28-day intervals, each with $1 \mathrm{mg}$ of purified Hrp pili in $1 \mathrm{ml}$ of a 1:1 mix of phosphate-saline and Freund's incomplete adjuvant. Serum was collected 14 days after each injection, and the titer and specificity of the antibody were checked by enzyme-linked immunosorbent assay and Western blotting. For preparation of antibody against the HrpA protein, the purified Hrp pili sample was electrophoresed in a large preparative sodium dodecyl sulfate (SDS)-15\% polyacrylamide gel. The gel portion containing the $10-\mathrm{kDa}$ HrpA protein was excised, and the HrpA protein was eluted from the gel slice with an electric elution apparatus (Schleicher \& Schuell, Keene, NH, U.S.A.). The procedure for antibody preparation was the same as for the production of the Hrp pilus antibody, except that $100 \mu \mathrm{g}$ of purified HrpA protein was used for each injection. Before immunoblotting or immunogold labeling, the Hrp pilus and HrpA antibodies were extensively absorbed with the total lysate of Pst DC3000 grown in LB agar, which represses the expression of hrp genes. Preparation of the HrpZ antibody was previously described (He et al. 1993). The HrpW antibody (Charkowski et al. 1998) was provided by A. Collmer at Cornell University.

\section{Cloning of the flaA gene and creation of a flaA mutant of Pst DC3000.}

A Pst DC3000 expression library constructed in pBluescript SK (Stratagene, La Jolla, CA, U.S.A.) was screened for the flagellin-encoding gene flaA with a rabbit polyclonal antibody against a mixture of Pst DC3000 extracellular proteins, including flagellin (Yuan and He 1996). One flagellin-producing clone was found to contain a $6-\mathrm{kb}$ insert. The flaA gene was localized to a restriction endonuclease designation (EcoRI)EcoRV fragment in the central region of the insert by subcloning and immunoblotting. A 422-bp DNA fragment containing part of the Pst DC3000 flaA gene was sequenced. The deduced amino acid sequence shares an overall $67 \%$ similarity with the Pseudomonas aeruginosa flagellin protein (Totten and Lory 1990). A flagellin-minus mutant (Table 1) of Pst DC3000 that contains a mini-Tn5Cm (De Lorenzo et al. 1990) insertion in the flaA gene was produced following a standard marker-exchange mutagenesis procedure (Yuan and He 1996). A flaAhrpA double mutant (Table 1) also was created by replacing the flaA gene in the hrpA mutant with the mutant flaA gene disrupted by the Tn $5 \mathrm{Cm}$ insertion.

\section{Immunogold labeling procedure.}

For immunogold labeling of Hrp pili formed in hrpinducing minimal agar medium, bacteria were first grown in $h r p$-inducing plates at $21^{\circ} \mathrm{C}$ for 2 to 3 days. Bacteria were then suspended in sterile water. A drop of bacterial suspension was applied to a copper grid coated with pioloform B (Wacker Polymer Systems GmbH \& Co., Adrian, MI, U.S.A.). The grid was incubated in $20 \mathrm{mM}$ Tris, $\mathrm{pH} 7.0,0.5 \%$ bovine serum albumin, and $0.05 \%$ Tween 20 (Tris-buffered saline [TBS] buffer) for $30 \mathrm{~min}$ at room temperature, followed by incubation for $2 \mathrm{~h}$ in TBS buffer containing the HrpA antibody at room temperature. The grid was then washed in TBS buffer four times for 5 min each time and incubated with goat antirabbit immunoglobulin G conjugated with $10 \mathrm{~nm}$ of gold particles (Sigma) for $2 \mathrm{~h}$. The grid was washed in TBS four times at 5 min each time and stained with $1 \%$ potassium phosphotungstic acid ( $\mathrm{pH} 7.0)$.

For immunogold labeling of Hrp pili assembled in bacteriainfected plant tissue, leaves of 4-week-old A. thaliana accession Columbia $(\mathrm{Col})$ plants were infiltrated with $1.5 \times 10^{9}$ bacteria per $\mathrm{ml}$ of the flaA or flaAhrpA mutant that was previously grown in LB medium. The infiltrated plants were kept at room temperature for HR or disease development. At various time points $(0,2,4,6$, and $8 \mathrm{~h})$ postinoculation, $1 \mathrm{~mm}^{2}$ of leaf samples were fixed for $2 \mathrm{~h}$ in $2 \%$ glutaraldehyde dissolved in $0.1 \mathrm{M}$ sodium cacodylate, $\mathrm{pH} 7.2$, at room temperature. The samples were postfixed with $1 \%$ osmium tetraoxide in $0.1 \mathrm{M}$

Table 1. Bacterial strains and plasmids used in this study

\begin{tabular}{|c|c|c|}
\hline Strain or plasmid & Relevant characteristics $^{\mathbf{a}}$ & Source or reference \\
\hline \multicolumn{3}{|l|}{ Escherichia coli } \\
\hline DH5 $\alpha$ & $\begin{array}{l}\mathrm{F}^{-} \phi 80 \mathrm{~d} l a c Z \Delta M 15 \Delta(\text { lacZYA-argF }) U 169 \text { deoR recA } \\
\quad \text { endA1 hsdR17 }\left(\mathrm{r}_{\mathrm{k}}^{-}, \mathrm{M}_{\mathrm{k}}\right) \text { phoA supE44 } \lambda^{-} \text {thi-1 gyrA96 } \\
\quad \text { relA1 }\end{array}$ & Life Sciences Technologies (Gaithersburg, MD, U.S.A.) \\
\hline \multicolumn{3}{|c|}{ Pseudomonas syringae pv. tomato } \\
\hline DC3000 & Wild type; $\mathrm{Rp}^{\mathrm{r}}$ & D. E. Cuppels \\
\hline hrpA & $\begin{array}{l}\text { hrpA deletion mutant of DC } 3000 ; \text { defective in the a s- } \\
\text { sembly of the Hrp pilus; } \mathrm{Rp}^{\mathrm{r}}, \mathrm{Km}^{\mathrm{r}} ; \mathrm{HR}^{-}, \mathrm{D}^{-}\end{array}$ & Roine et al. 1997 \\
\hline flaA & $\begin{array}{l}\text { flaA mutant of DC3000; defective in the assembly of } \\
\text { the flagellar filament; } \mathrm{Rp}^{\mathrm{r}}, \mathrm{Cm}^{\mathrm{r}} ; \mathrm{HR}^{+}, \mathrm{D}^{+}\end{array}$ & This study \\
\hline flaAhrpA & $\begin{array}{l}\text { hrpAflaA double mutant of DC } 3000 \text {; defective in the } \\
\text { assembly of the Hrp pilus and the flagellar filament; } \\
\mathrm{Rp}^{\mathrm{r}}, \mathrm{Cm}^{\mathrm{r}}, \mathrm{Km}^{\mathrm{r}} ; \mathrm{HR}^{-}, \mathrm{D}^{-}\end{array}$ & This study \\
\hline \multicolumn{3}{|c|}{ 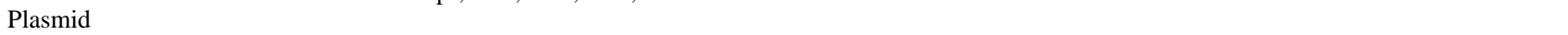 } \\
\hline pBluescript SK & ColE1 Ap ${ }^{\mathrm{r}}$ mcs-lac Z & Stratagene, La Jolla, CA, U.S.A. \\
\hline
\end{tabular}

${ }^{a} \mathrm{HR}=$ ability to cause the hypersensitive response, which is characterized by rapid, localized tissue collapse in the bacteria-infiltrated area in tobacco leaves. $\mathrm{D}=$ ability to cause disease symptoms (tissue chlorosis and slow necrosis) in Arabidopsis thaliana. 
sodium cacodylate, $\mathrm{pH} \mathrm{7.2,} \mathrm{for} 2 \mathrm{~h}$ at room temperature, followed by dehydration in a series of acetone dilutions and embedded in the resin Spurtol. Ultrathin sections of 70 to $90 \mathrm{~nm}$ were cut with a diamond knife and placed on uncoated nickel grids. Grids were then processed as described above, except that the grids were pretreated with a saturated aqueous solution of sodium metaperiodate (Sigma) before incubation with TBS buffer (Bendayan and Zollinger 1983). Before examination by electron microscopy, grids were poststained with $1 \%$ uranyl acetate for $30 \mathrm{~min}$, rinsed in distilled water, and stained with Hanaichi's lead solution (Hanaichi et al. 1986) for $5 \mathrm{~min}$, followed by rinsing in $20 \mathrm{mM} \mathrm{NaOH}$ and distilled water. After staining, grids were observed with a CM10 transmission electron microscope (Philips, Eindhoven, The Netherlands). Micrographs were taken at an accelerating voltage of $80 \mathrm{kV}$.

\section{Pathogenesis assays.}

Bacteria were grown in LB broth to an optical density of 0.6 to 0.8 at $600 \mathrm{~nm}$. Bacterial suspensions in distilled water were infiltrated into leaves of $\mathrm{Col}$ and tobacco (Nicotiana tabacum cv. Samsun NN) with needleless syringes. The bacteria concentrations were $2 \times 10^{8}$ and $2 \times 10^{6} \mathrm{CFU} / \mathrm{ml}$ for HR and pathogenesis assays, respectively. Plant responses were recorded at $24 \mathrm{~h}$ for HR assay or 4 days for pathogenesis assay postinfiltration. HR was indicated by rapid, localized tissue collapse in the infiltrated area within $24 \mathrm{~h}$. Disease symptoms caused by Pst DC3000 in A. thaliana leaves were characterized by slowly developing necrosis and spreading tissue chlorosis, usually observed 3 days after infiltration. Plants postinoculation were kept in the laboratory at room temperature for the development of disease or HR.

\section{ACKNOWLEDGMENTS}

We thank J. Heckman and S. Burns at the Center for Optical Electronics at Michigan State University for their expert help with electron microscopy techniques. We are grateful to Q. Yuan for his assistance in the preparation of antibodies, K. Bird for her help in preparing this paper, and J. Mansfield and M. Romantchuk for very useful discussions and exchange of data prior to publication. This work was supported by grants from the U.S. Department of Energy and Department of Agriculture.

\section{LITERATURE CITED}

Alfano, J. R., and Collmer, A. 1997. The type III (Hrp) secretion pathway of plant pathogenic bacteria: Trafficking harpins, Avr proteins, and death. J. Bacteriol. 179:5655-5662.

Bendayan, M., and Zollinger, M. 1983. Ultrastructural localization of antigenic sites on osmium-fixed tissues applying the protein A-gold technique. J. Histochem. Cytochem. 31:101-109.

Blocker, A., Gounon, P., Larquet, E., Niebuhr, K., Cabiaux, V., Parsot, C., and Sansonetti, P. 1999. The tripartite type III secretion of Shigella flexneri inserts IpaB and IpaC into host membranes. J. Cell Biol. 147:683-693.

Bogdanove, A. J., Beer, S. V., Bonas, U., Boucher, C. A., Collmer, A., Coplin, D. L., Cornelis, G. R., Huang, H.-C., Hutcheson, S. W., Panopoulos, N. J., and Van Gijsegem, F. 1996. Unified nomenclature for broadly conserved hrp genes of phytopathogenic bacteria. Mol. Microbiol. 20:681-683.

Bonas, U. 1994. hrp genes of phytopathogenic bacteria. Curr. Top. Microbiol Immunol. 192:79-98.

Brown, I. R., Mansfield, J. W., Taira, S., Roine, E., and Romantschuk, M. 2001. Immunocytochemical localization of HrpA and HrpZ supports a role for the Hrp pilus in the transfer of effector proteins from Pseudomonas syringae pv. tomato across the host plant cell wall. Mol.
Plant-Microbe Interact. In press.

Charkowski, A. O., Alfano, J. R., Preston, G., Yuan, J., He, S. Y., and Collmer, A. 1998. The Pseudomonas syringae pv. tomato HrpW protein has domains similar to harpins and pectate lyases and can elicit the plant hypersensitive response and bind to pectate. J. Bacteriol. 180:5211-5217.

De Lorenzo, V., Herrero, M., Jakubzik, U., and Timmis, K. N. 1990. Mini-Tn5 transposon derivatives for insertion mutagenesis, promoter probing, and chromosomal insertion of cloned DNA in Gram-negative eubacteria. J. Bacteriol. 172:6568-6572.

Ebel, F., Podzadel, T., Rohde, M., Kresse, A. U., Kramer, S., Deibel, C., Guzman, C. A., and Chakraborty, T. 1998. Initial binding of Shiga toxin-producing Escherichia coli to host cells and subsequent induction of actin rearrangements depend on filamentous EspA-containing surface appendages. Mol. Microbiol. 30:147-161.

Fullner, K. J., Lara, J. C., and Nester, E. W. 1996. Pilus assembly by Agrobacterium T-DNA transfer genes. Science 273:1107-1109.

Galan, J. E., and Collmer, A. 1999. Type III secretion machines: Bacterial devices for protein delivery into host cells. Science 284:13221328.

Ginocchio C., Olmsted, S. B., Wells, C. L., and Galan, J. E. 1994. Contact with epithelial cells induces the formation of surface appendages on Salmonella typhimurium. Cell 76:717-724.

Goodman, R. N. 1982. The infection process. Pages 31-62 in: Phytopathogenic Prokaryotes, Vol. 1. M. S. Mount and G. H. Lacy, eds. Academic Press, New York.

Hanaichi, T., Sato, T., Iwamoto, T., Malavasi-Yamashiro, J., Hoshino, M., and Mizuno, N. 1986. A stable lead by modification of Sato's method. J. Electron. Microsc. 35:304-306.

He, S., Huang, H., and Collmer, A. 1993. Pseudomonas syringae pv. syringae harpin ${ }_{\text {Pss: }}$ : A protein that is secreted via the Hrp pathway and elicits the hypersensitive response in plants. Cell 73:1255-1266.

He, S. Y. 1997. Hrp-controlled interkingdom protein transport: Learning from flagellar assembly? Trends Microbiol. 5:489-495.

He, S. Y. 1998. Type III secretion systems in animal and plant pathogenic bacteria. Annu. Rev. Phytopathol. 36:363-392.

Hoyos, M. E., Stanley, C. M., He, S. Y., Pike, S., Pu, X.-A., and Novacky, A. 1996. The interaction of harpin ${ }_{\text {Pss }}$, with plant cell walls. Mol. Plant-Microbe Interact. 9:608-616.

Huang, H., Lin, R., Chang, C., Collmer, A., and Deng, W. 1995. The complete hrp gene cluster of Pseudomonas syringae pv. syringae 61 includes two blocks of genes required for harpin Pss $_{\text {secretion that are }}$ arranged colinearly with Yersinia ysc homologs. Mol. Plant-Microbe Interact. 8:733-746.

Hutcheson, S. W. 1999. The hrp genes of Pseudomonas syringae: A pathogenicity island encoding a type III protein translocation complex? Pages 309-330 in: Pathogenicity Islands and Other Mobile Virulence Elements. J. B. Kaper and J. Hacker, eds. American Society for Microbiology, Washington, DC.

Knutton S, Rosenshine, I., Pallen, M. J., Nisan, I., Neves, B. C., Bain, C., Wolff, C., Dougan, G., and Frankel, G. 1998. A novel EspAassociated surface organelle of enteropathogenic Escherichia coli involved in protein translocation into epithelial cells. EMBO J. 17:2166-2176.

Kubori, T., Matsushima, Y., Nakamura, D., Uralil, J., Lara-Tejero, M., Sukhan, A., Galan, J. E., and Aizawa, S. I. 1998. Supramolecular structure of the Salmonella typhimurium type III protein secretion system. Science 280:602-605.

Lindgren, P. B. 1997. The role of hrp genes during plant-bacterial interactions. Annu. Rev. Phytopathol. 35:129-152.

Mudgett, M. B., and Staskawicz, B. J. 1999. Characterization of the Pseudomonas syringae pv. tomato AvrRpt2 protein: Demonstration of secretion and processing during bacterial pathogenesis. Mol. Microbiol. 32:927-941.

Perino, C., Gaudriault, S., Vian, B., and Barny, M. A. 1999. Visualization of harpin secretion in planta during infection of apple seedlings by Erwinia amylovora. Cell. Microbiol. 1:131-141.

Rahme, L. G., Mindrinos, M. N., and Panopoulos, N. J. 1992. Plant and environmental sensory signals control the expression of hrp genes in Pseudomonas syringae pv. phaseolicola. J. Bacteriol. 174:3499-3507.

Roine, E., Saarinen, J., Kalkkinen, N., and Romantschuk, M. 1998. Purified HrpA of Pseudomonas syringae pv. tomato DC3000 reassembles into pili. FEBS Lett. 417:168-172.

Roine, E., Wei, W., Yuan, J., Nurmiaho-Lassila, E.-L., Kalkkinen, N., 
Romantschuk, M., and He, S. Y. 1997. Hrp pilus: An hrp-dependent bacterial surface appendage produced by Pseudomonas syringae pv. tomato DC3000. Proc. Natl. Acad. Sci. USA 94:3459-3464.

Soto, G. E., and Hultgren, S. J. 1999. Bacterial adhesins: Common themes and variations in architecture and assembly. J. Bacteriol 181:1059-1071.

Totten, P. A., and Lory, S. 1990. Characterization of the type a flagellin gene from Pseudomonas aeruginosa PAK. J. Bacteriol. 172:7188-7199.

Van Dijk, K., Fouts, D. E., Rehm, A. H., Hill, A. R., Collmer, A., and Alfano, J. R. 1999. The Avr (effector) proteins HrmA (HopPsyA) and AvrPto are secreted in culture from Pseudomonas syringae pathovars via the Hrp (type III) protein secretion system in a temperature- and pH-sensitive manner. J. Bacteriol. 181:4790-4797.

Van Gijsegem, F., Vasse, J., Camus, J. C., Marenda, M., and Boucher, C. 2000. Ralstonia solanacearum produces Hrp-dependent pili that are required for PopA secretion but not for attachment of bacteria to plant cells. Mol. Microbiol. 36:249-260.

Wei, W., Plovanich-Jones, A., Deng, W.-L., Collmer, A., Huang, H.-C., and He, S. Y. 2000. The gene coding for the structural protein of the Hrp pilus is required for secretion of Hrp and Avr proteins in Pseudomonas syringae pv. tomato. Proc. Natl. Acad. Sci. USA 97:22472252.

Willetts, N., and Skurray, R. 1980. The conjugation system of F-like plasmids. Annu. Rev. Genet. 14:41-76.

Xiao, Y., Lu, Y., Heu, S., and Hutcheson, S. W. 1992. Organization and environmental regulation of the Pseudomonas syringae pv. syringae 61 hrp cluster. J. Bacteriol. 174:1734-1741.

Yuan, J., and He, S. Y. 1996. The Pseudomonas syringae hrp regulation and secretion system controls the production and secretion of multiple extracellular proteins. J. Bacteriol. 178:6399-6402. 